\title{
Research on durability of turning tools made of low-alloy high-speed steels
}

\author{
J. Jaworski, T. Trzepieciński \\ Faculty of Mechanical Engineering and Aeronautics, Rzeszow University of Technology, \\ Al. Powstańców Warszawy 12, 35-959 Rzeszów, Poland
}

Received 4 August 2014, received in revised form 16 March 2015, accepted 30 March 2015

\begin{abstract}
This paper presents the results of investigations of temperature field distribution in the cutting edge and yield strength of tool material for low-alloy high-speed steels. Investigations of temperature distribution in cutting edges were made during C60 steel turning using a semi-natural constantan thermo-element. The obtained results show that the decrease in addition alloy content does not influence the change in thermal-physical properties of lowalloy high-speed steels. Investigations of the durability of cutting edges confirm that to define working conditions of the tool made of high-speed steel, resistance against hardness loss with increasing temperature at temperatures higher and lower than tempering temperature is the most significant. The results of durability investigations of cutters made of HS3-1-2 steel with various kinds of surface treatment confirm the reasons for cutting edge wear of tools made of high-speed steel and ways of the increasing their durability.
\end{abstract}

K e y words: deformation, high temperature, powder processing, steels, wear

\section{Introduction}

The high cost of alloy additions caused by a deficit of tungsten (W), molybdenum (Mo), cobalt (Co) and vanadium $(\mathrm{V})$ means that the assurance of such important material properties as hardness, strength, temperability, thermal conductivity and grindability becomes more and more uncertain. On the other hand, in mechanical engineering high-alloyed construction materials are used more often, and these chemical elements are needed. From this aspect, the economical management of these alloyed elements is a very important issue. One of the ways to solve this problem is through further development of the use of economical high-speed steels and modern metal finishing $[1,2]$. High-speed steels are complex iron-base alloys containing carbon, tungsten, molybdenum, vanadium, chromium and substantial amounts of cobalt [3, 4]. Applied high-speed steels used for 100 years are nowadays of increasingly limited use as cutting tools (especially at high machining speeds) but they are used for constructional elements, as tools for plastic forming, and in forms to manufacture products made of plastic $[5$, $6]$.

The reduction of alloy additions in high-speed steels does not necessarily indicate deterioration in the quality of tools made from these steels. It is a well-known fact that a larger percentage of tungsten in high-speed steels causes reduction of thermal conductivity, as presented in Table 1. Therefore, at higher machining speeds, thanks to better heat dissipation from the cutting area, tools made of HS9-0-2 steel are more effective than comparable tools made of HS18$0-1$ steel $[7,8]$. To ensure applicable quality requirements during the production of tools made of low-alloy high-speed steels, it is very important that their cutting ability is not lower than that of comparable tools made of classic high-speed steels. This requires work conditions of a high standard to be established so that they can compete effectively with classic high-speed steels [9].

In the development of high-speed steels, three basic directions are evident:

- improvement of production technology for the purpose of enabling the use of more and more com-

*Corresponding author: tel.: +4817 8651714; e-mail address: tomtrz@prz.edu.pl 
Ta ble 1. New low-alloy high-speed steel grades - chemical constitution and physical-mechanical properties

\begin{tabular}{|c|c|c|c|c|c|}
\hline \multirow{2}{*}{ Steel grade ${ }^{1}$} & \multicolumn{5}{|c|}{ Chemical constitution (\%) } \\
\hline & $\mathrm{C}$ & $\mathrm{W}$ & Mo & $\mathrm{Cr}$ & $\mathrm{V}$ \\
\hline HS3-3-2 & $1.0-11$ & $2.5-3.0$ & $2.5-3.0$ & $3.8-4.42$ & $2.1-2.7$ \\
\hline HS2-5-1 & $0.9-1.0$ & $1.5-2.0$ & $4.5-5.5$ & $3.50-4.50$ & $1.10-1.40$ \\
\hline HS3-1-2 & $1.1-1.2$ & $3.1-3.4$ & $1.1-1.2$ & $4.3-4.7$ & $1.6-1.8$ \\
\hline HS12-0-2 & $1.05-1.15$ & $11.00-13.00$ & - & $3.50-4.50$ & $2.20-2.70$ \\
\hline HS6-5-2 & $0.82-0.92$ & $6.00-7.00$ & $4.50-5.50$ & $3.50-4.50$ & $1.70-2.10$ \\
\hline HS18-0-1 & $0.75-0.85$ & $17.0-19.0$ & - & $3.50-4.50$ & $1.0-1.4$ \\
\hline HS9-0-2 & $0.80-0.95$ & $8.0-10.0$ & - & $3.5-4.5$ & $1.8-2.2$ \\
\hline
\end{tabular}

${ }^{1}$ Designation according to EN-10027-1:2005 (Designation systems for steels - Part 1: Steel names)

plex grades of chemical constitution and more uniform structure;

- ensuring better technological properties for these steels; $[4]$.

- developing economical, cheaper high-speed steels

Low-alloy high-speed steels are a subgroup among the high-speed steels, generally having the content \% $\mathrm{W}+1.5 \%$ Mo $<12 \%$.

The selection of material for a suitable tool is dependent on the method of its wear or destruction. This selection is facilitated by characteristics describing relations between the tool material structure and properties and work conditions of the tool and the method of its wear. It is very important to establish for selected tools attributes of suitable physical and mechanical properties. It is also significant to establish criteria for tool wear and to establish suitable requirements regarding the structure and properties of the tool material [10]. The data about life of tools made of low-alloyed high-speed steels presented in publications do not have any scientific justification, and they are also inconsistent. In many papers, the machining parameters used during research are not provided. Machining speeds are still increasing, and this tendency will continue at the same level in the future. Therefore, to define an area of use and selection of optimal machining parameters, it is necessary to recognize temperature and force conditions of their work. By understanding these conditions, the basic reasons for tool wear (depending on specific work conditions) can be defined and the most effective methods of wear reduction can be proposed.

In recent years increasing interest in:

- machining at high cutting speed;

- very precise machining;

- machining of hard machinable materials (hardened steels, high alloy cast iron, sintered carbides);

- machining without cooling;

- machining at high speed (high-speed machining);

- machining at high feed (high-performance machining) has been observed.

This requires tool materials assuring a set of such important properties as hardness, strength, temperability and thermal conductivity, and tungsten (W), cobalt $(\mathrm{Co})$, molybdenum $(\mathrm{Mo})$ and vanadium $(\mathrm{V})$ are required. On the other hand, also in mechanical engineering high-alloy structural materials that require these elements are used more widely. In this situation, economical management of these alloy elements is an important task. One of the ways to solve this problem is through further development of economical high-speed steels and application of modern surface treatments. Cutting tools made of high-speed steels still make up about $50 \%$ of the general number of tools [11]. Therefore, a decrease in the content of the above-mentioned alloy additives in this material class could provide the most noticeable effect. The highspeed steels used for about 100 years now have an increasingly narrow application for cutting tools (particularly at high cutting speed) but they are more and more widely used for structural elements, forming tools and for plastic product forms.

Regarding monitoring systems and high-speed machining, the investigation of thermal phenomena of cutting processes is currently very important [1214]. Cutting temperature measuring methods exist that use thermocouples and infrared measuring systems [15]. The main techniques used to evaluate temperature during machining have been reviewed by O'Sullivan and Cotterell [16]. Thermocouples are very rugged and inexpensive and can operate over a wide temperature range [16]. This technique is easy to apply, but it only measures the mean temperature over the entire contact area [17]. The distribution of temperature in cutting edge material during machining can be defined in selected places with the use of a thermocouple. The measurement of arisen heat during machining is determined analytically as a measured temperature distribution and the thermal properties of cutting edge and workpiece, which are known. The knowledge of temperature distribution and thermal flux process is the one of the factors influencing tool life [18].

The attempts at developing and introducing economical high-speed steels refer to the date back to the 
Table 2. Selected physical-mechanical properties of low-alloy high-speed steel grades

\begin{tabular}{lcccc}
\hline Steel grade & $\begin{array}{c}\text { Hardness } \\
\text { HRC }\end{array}$ & $\begin{array}{c}\text { Bending strength } \\
R g(\mathrm{MPa})\end{array}$ & $\begin{array}{c}\text { Impact resistance } \\
U\left(\mathrm{~J} \mathrm{~m}^{-2}\right)\end{array}$ & $\begin{array}{c}\text { Hardening temperature } \\
T_{\mathrm{h}}\left({ }^{\circ} \mathrm{C}\right)\end{array}$ \\
\hline HS3-3-2 & 64 & $3400-3800$ & $3.2 \times 10^{5}-4 \times 10^{5}$ & $1180-1210$ \\
HS2-5-1 & 64 & $3000-3400$ & $4 \times 10^{5}-4.5 \times 10^{5}$ & $1080-1170$ \\
HS3-1-2 & $63-68$ & $3000-3600$ & $4.6 \cdot 10^{5}$ & $1080-1170$ \\
HS12-0-2 & 64 & $3000-3200$ & $3.8 \cdot 10^{5}$ & $950-970$ \\
HS6-5-2 & 64 & $3200-3600$ & $4.8 \cdot 10^{5}$ & $1200-1230$ \\
\hline
\end{tabular}

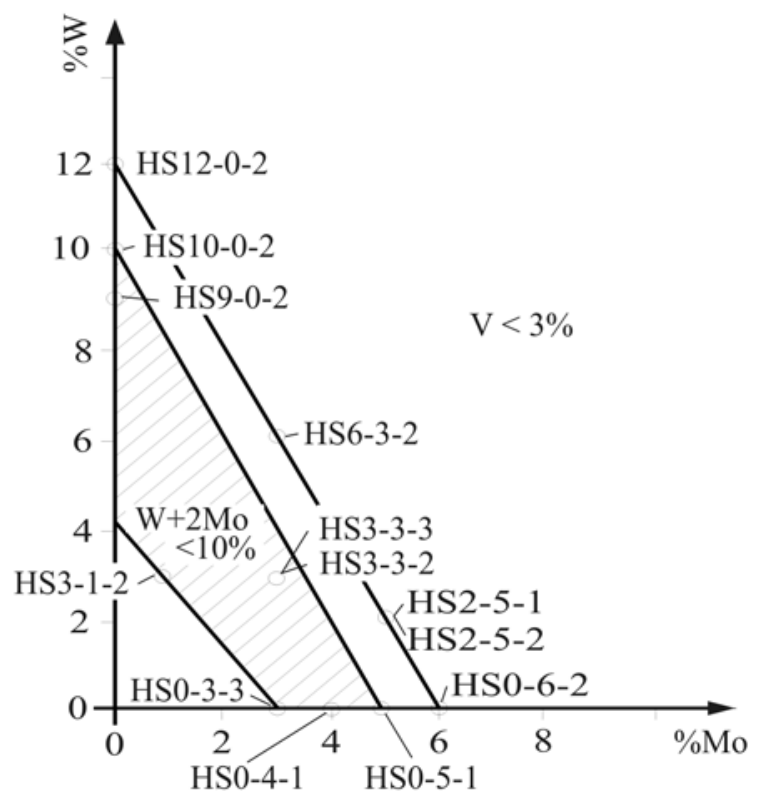

Fig. 1. Appearance ranges of low-alloy high-speed steels, prepared on the basis of [4].

1940s. At this time, many low-alloy high-speed steel grades were developed, which, however, have not been much used in industry, the reason being, first, their poorer technological properties, such as too narrow range of hardening temperature, a large quantity of retained austenite after finishing heat treatment, bad grindability and tendency to decarburization. The appearance range of low-alloy high-speed steels is presented in Fig. 1.

\section{Investigation of thermal processes of turning tools}

\subsection{Materials}

The investigation of the temperature field distribution in the cutting edge, the durability of cutting edge and yield strength of tool material were carried out for low-alloy high-speed steels. Their chemical constitution and selected physical-mechanical properties are presented in Table 1 and Table 2, respectively.

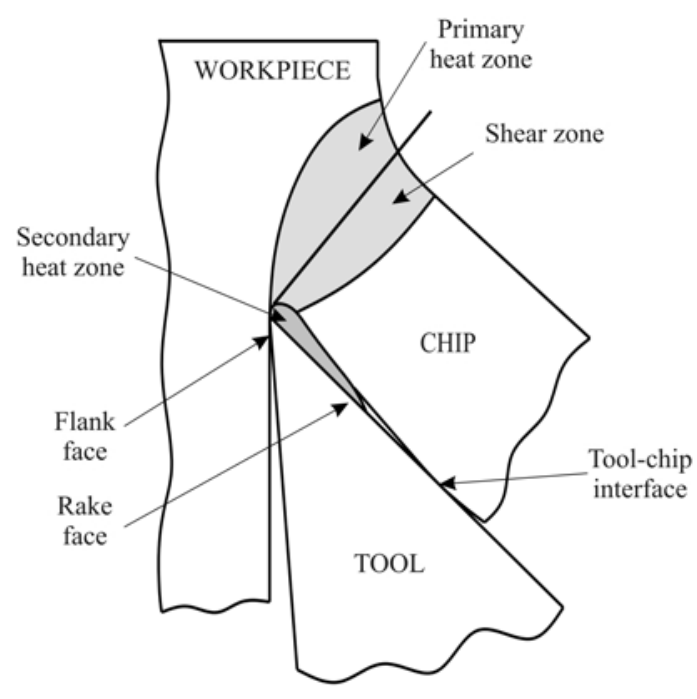

Fig. 2. Regions of heat generation in turning.

\subsection{Methods}

Three regions of heat generation can be distinguished in turning; the shear zone, the chip-tool interface and the tool-workpiece interface (Fig. 2). The primary shear zone temperatures affect the mechanical properties of the workpiece-chip material and temperatures at the tool-chip and tool-workpiece interfaces influence tool wear [16].

Research into temperature distribution in a cutting edge made of HS3-1-2 and HS6-5-2 steels during C60 steel turning using semi-natural constantan thermoelement (with cutting edge material) was carried out by the following method: sectional cutters from both grades of steel with hardness $\sim 63.5 \mathrm{HRC}$ were specially prepared [9]. The parting plane was crossed perpendicularly to the main cutting edge in the middle of the contact surface between the chip and rake surface, where the highest temperature was recorded [11]. For preparing the thermo-element, the $\varnothing 0.1 \mathrm{~mm}$ diameter constantan wire was flattened at the end to dimensions: $0.15 \times 0.15 \times 0.005 \mathrm{~mm}^{3}$ and it was isolated. The distance from the middle of the contact weld to the tool flank and the rank surface was measured with $0.01 \mathrm{~mm}$ precision on the microscope. The tempera- 
ture was measured following stabilization using a millivoltmeter, which was set up to Celsius degrees. To obtain the thermometric characteristic of the constantan thermo-element, the set-up was achieved by locating the thermocouple in the medium with the known temperature.

\subsection{Results and discussion}

The method of wear or destruction of the tool determines material selection for a proper tool. This selection is facilitated by the characteristics, which determine the relations between the structure and the properties of tool material on the one hand and tool working conditions and the method of wear on the other [16]. It is very important to define adequate physical and mechanical properties for the selected tool features as the characteristics of resistance [19]. It is also important to establish wear criteria as well as adequate requirements regarding structure and properties of tool material. Data presented in the literature regarding the durability of low-alloy high-speed steel tools are not scientifically substantiated, and they are often inconsistent. In several publications, even cutting parameters are not provided in the investigations conducted. Considering that cutting speed is still increasing, and that tendency will continue in the future, it is necessary to be familiar with the temperatureforce conditions of tool work to establish the application field and to select optimum machining parameters. If these conditions are known, then there is a possibility to establish the basic reasons for wear (depending on definite work conditions) and to propose the most effective ways to increase durability.

Reduction of contents of alloying additions in highspeed steels does not have to mean deterioration in the quality of the tools made of these steels. It is generally known, for example, that greater tungsten content in high-speed steel causes reduction of thermal conductivity and, therefore, the tools made of HS9-0-2 steel have been more effective than comparable tools made of HS18-0-1 steel at greater cutting speed as a result of being better able to carry away the heat from the cutting zone [20]. It is very important for assurance of quality production of low-alloy high-speed steel tools that their cutting performance is not less than the cutting performance of comparable tools made of conventional high-speed steels, what requires particular work conditions to be determined to compete successfullæhe permissible cutting speed level is determined first of all by the temperature that arises on the contact surface of the tool with the stock material. There is a relationship between the temperature and wear of the cutting edge surface of the tool caused by progressive loss of its hardness. When the temperature in the cutting process exceeds the value at which the cutting edge of the tool loses its hardness, then dynamic re-

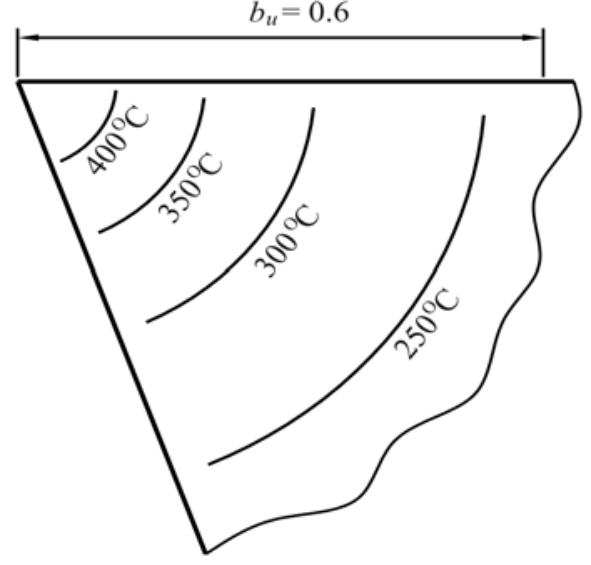

Fig. 3. Distribution of temperature fields on the cutting edge of the cutter made of HS6-5-2 steel at small cut layer thickness: $v_{\mathrm{c}}=50 \mathrm{~m} \mathrm{~min}{ }^{-1}, f=0.08 \mathrm{~mm} \mathrm{rev}^{-1}, a_{\mathrm{p}}=$ $2 \mathrm{~mm}, T_{\mathrm{c}}=450 \mathrm{~min}$.

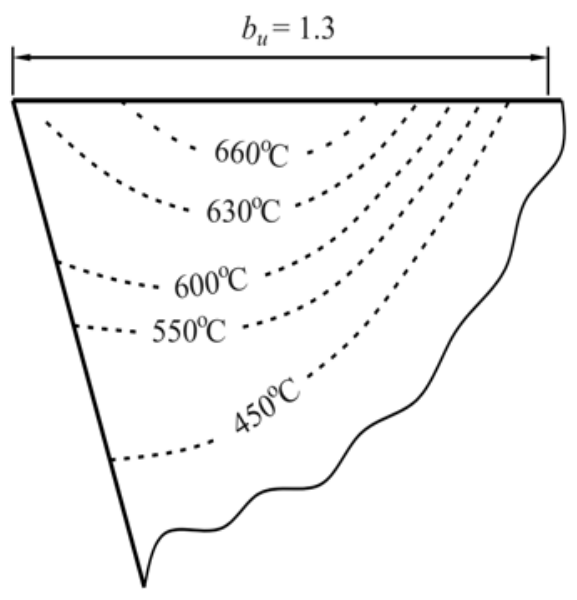

Fig. 4. Distribution of temperature fields on the cutting edge of the cutter made of HS6-5-2 steel at large cut layer thickness: $v_{\mathrm{c}}=28 \mathrm{~m} \mathrm{~min}^{-1}, f=0.3 \mathrm{~mm} \mathrm{rev}^{-1}, a_{\mathrm{p}}=2 \mathrm{~mm}$, $T_{\mathrm{c}}=300 \mathrm{~min}$.

crystallization causes its immediate catastrophic wear, even at an inconsiderable value of dullness. The distribution of the temperature in the cutting edge of the cutter made of HS6-5-2 steel while turning C60 steel is presented in Fig. 3 and proves that the nature of temperature distribution conditions the place of wear of the cutting edge. At small cut layer thickness, the maximum temperature arises near the cutting edge that is the reason for wear of the cutting edge on the back-off surface. Together with raising thickness of the cut layer the highest temperature displaces out of the cutting edge and its centre lies at the place of contact of the chip with the rake surface (Fig. 4). For such cutting conditions, wear in the form of a groove on the rake surface is characteristic. For the same tool mate- 
(a)

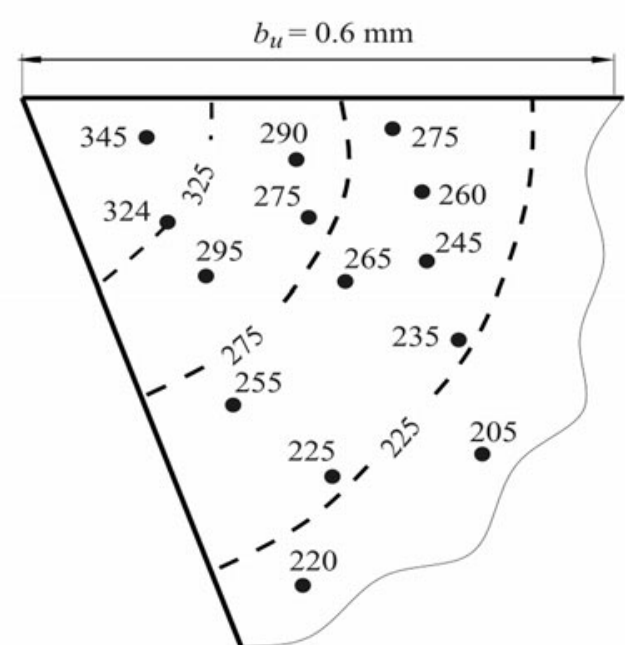

(b)

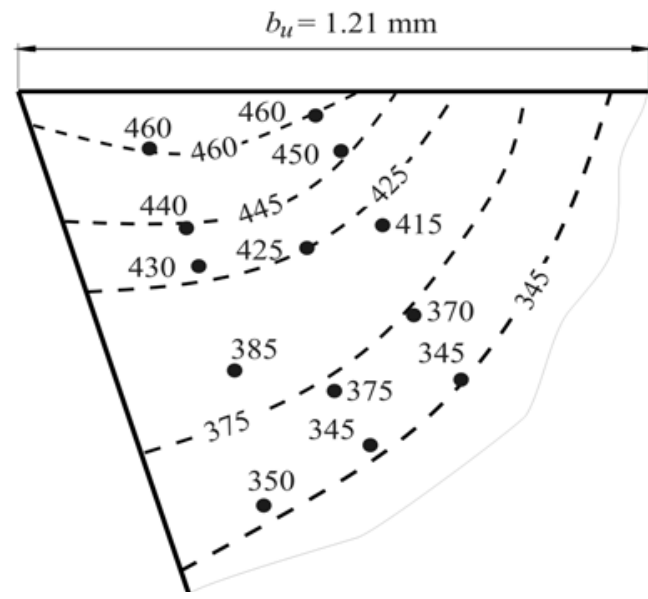

Fig. 5. Distribution of temperature fields in the cutting edge of the cutter made of HS3-1-2 steel: a) small cut layer thickness at: $v_{\mathrm{c}}=47 \mathrm{~m} \mathrm{~min}^{-1}, f=0.08 \mathrm{~mm} \mathrm{rev}^{-1}, a_{\mathrm{p}}=$ $\left.2 \mathrm{~mm}, T_{\mathrm{c}}=60 \mathrm{~min}, \mathrm{~b}\right)$ large cut layer thickness at: $v_{\mathrm{c}}=$ $25 \mathrm{~m} \mathrm{~min}^{-1}, f=0.3 \mathrm{~mm} \mathrm{rev}^{-1}, a_{\mathrm{p}}=2 \mathrm{~mm}, T_{\mathrm{c}}=15 \mathrm{~min}$.

rial and stock material, the thickness of the cut layer has an influence on the type of temperature distribution and cutting speed on its value. On the basis of this research in the paper [11] a systematisation of reasons for tool wear has been made that can be assumed to be the methodological basis for analysing the cutting ability of tools made of low-alloy high-speed steel and for choosing the most rational ways to increase their durability.

Figure 5 presents the distribution of temperature fields on the cutting edge of the cutter made of HS31-2 steel during turning of C60 steel under the same conditions as of the temperature fields on the cutting edge of the cutter made of HS6-5-2 steel. At small cut layer thickness, when the feed value $f=0.08 \mathrm{~mm} \mathrm{rev}^{-1}$ (Fig. 5a), the maximum temperature occurs near the main cutting edge on the clearance surface side and it is a little lower at the cutting edge of the cutter made of HS3-1-2 steel by reason of lower cutting speed $\left(v_{\mathrm{c}}=\right.$ $\left.47 \mathrm{~m} \mathrm{~min}^{-1}\right)$. The almost equal temperature gradient for both cutting edges can be indirect evidence of equal thermal conductivity of both materials. Even at the extent of contact of the chip on the rake surface $\left(b_{\mathrm{u}}\right)$ the temperature value decreases decidedly which means that the tip is the most loaded part of the cutting edge. At a large thickness of the cut layer, when the feed value $f=0.34 \mathrm{~mm} \mathrm{rev}^{-1}$ (Fig. 5b), the maximum temperature lies on the rake surface and it is also lower than in the cutting edge made of HS6-5-2 steel because of lower cutting speed $v_{\mathrm{c}}=25 \mathrm{~m} \mathrm{~min}^{-1}$. The temperature gradient is also equal for both cutting edges.

The comparison of durability of the cutting edges of cutters made of these steels has proven that durability of the cutter edge made of HS3-1-2 steel during straight turning of C60 steel at $v_{\mathrm{c}}=47 \mathrm{~m} \mathrm{~min}^{-1}$, cutting depth $a_{\mathrm{p}}=2 \mathrm{~mm}, f=0.08 \mathrm{~mm} \mathrm{rev}^{-1}$ and at the wear at back-off surface $\mathrm{VB}=0.5 \mathrm{~mm}$ amounts to $T_{\mathrm{c}}=60 \mathrm{~min}$ and for the cutter made of HS6-5-2 steel, to $T_{\mathrm{c}}=450 \mathrm{~min}$. When turning at $f=0.3 \mathrm{~mm} \mathrm{rev}^{-1}$ and $v_{\mathrm{c}}=25 \mathrm{~m} \mathrm{~min}^{-1}$, durability of the cutter edge made of HS3-1-2 steel amounts to $T_{\mathrm{c}}=15 \mathrm{~min}$ and durability of the cutter edge made of HS6-5-2 steel, to $T_{\mathrm{c}}=300 \min [20]$.

The obtained results show that the decrease of alloy additions content has not affected the thermalphysical properties of HS3-1-2 steel (temperature gradient and distribution equal for both cutting edge material grades), and the cause of such a large difference in the durability of cutters should be sought in the lower temperability of HS3-1-2 steel. It can be supposed that for the tools made of low-alloy highspeed steels, the main reason limiting their use at high cutting speed is the loss of hardness and the plastic deformation of the cutter edge that causes catastrophic wear to occur at a lower cutting speed than for HS65-2 steel.

\section{Yield strength of low-alloy high-speed steels}

One of the most important characteristics of highspeed steel showing how steel keeps its hardness under the influence of temperature is temperability [21]. Examining temperability consists of determining the hardness of samples that have been previously heat treated after maintaining at a temperature of $620^{\circ} \mathrm{C}$ for $4 \mathrm{~h}$. According to the GOST19265 standard, highspeed steels should have hardness over $58 \mathrm{HRC}$ after tempering at a temperature of $620^{\circ} \mathrm{C}$ for $4 \mathrm{~h}$. It is known that hardness measurement at ambient temperature after previous heating to a temperature of $620^{\circ} \mathrm{C}$ is a reverberation of only those changes in a 
steel structure that are caused by irreversible transformations (martensite decomposition and carbide coagulation) [22]. In this case, reversible transformations are not taken into account; they are not of major importance at lower temperatures. However, if tool working temperature lies near the temperability limit of a given steel grade, then reversible transformations increase steel tendency to plastic deformation and affect tool cutting edge stability [22]. It is known that high-speed cobalt steels allow increasing tool edge durability on machining austenitic steels from two to four times, although their temperability is not much greater compared to HS18-0-1 steel. Their advantage is increased resistance to hardness decrease within the range of irreversible as well as reversible transformations that is especially important when machining hardly machinable materials, where high temperatures and high local stresses arise in the cutting zone. Considering the above, the explanation of the reason for such a large durability difference must be sought in the resistance of this steel to hardness decrease in the range of both reversible and irreversible transformations, that is, its hot hardness must be measured. One of the best-known methods of hot hardness measurement is that of the Vickers method on apparatus with a vacuum chamber especially modernised for this purpose. Diagonal measurement is made after pulling out the sample from the chamber and cooling.

It is possible to use an indirect method for the evaluation of hot hardness. It is known from the professional literature [23] that, depending on temperature, yield strength $R_{0.2}$ changes in the same way as hardness. Knowing $R_{0.2}$ at a given temperature, what passes for hardness at this temperature can be supposed. This method also has the advantage that there are standard devices for measuring strength at a raised temperature, eliminating the possibility of committing subjective errors that are a cause of considerable differences in hot hardness values according to various authors [23, 24].

Figure 6 presents measurement results of $R_{0.2}$ vs. temperature for selected high-speed steel grades according to the method described in the paper [24]. Analysing the results of measurements, three characteristic ranges of the $R_{0.2}$ decrease can be distinguished.

First range: insignificant $R_{0.2}$ decrease $\sim 50 \mathrm{MPa}$ for each $100^{\circ} \mathrm{C}$. This range for HS6-5-2 steel spreads to a temperature of $500^{\circ} \mathrm{C}$, for HS2-5-1 and HS3-3-2 steels to $450{ }^{\circ} \mathrm{C}$ and for $\mathrm{HS} 3-1-2$ steel to $400{ }^{\circ} \mathrm{C}$.

Second range: for $\mathrm{HS} 6-5-2$ steel $R_{0.2}$ decrease $\sim 350 \mathrm{MPa}$ for each $100^{\circ} \mathrm{C}$ and this range spreads to $600{ }^{\circ} \mathrm{C}$, whereas for HS2-5-1, HS3-3-2 and HS3-1-2 steels this decrease is more intensive, $550 \mathrm{MPa}$, and it takes place in the temperature range of $500-550^{\circ} \mathrm{C}$ for HS2-5-1 and HS3-3-2, and 450-550 ${ }^{\circ} \mathrm{C}$ for HS3-1-2 steel.

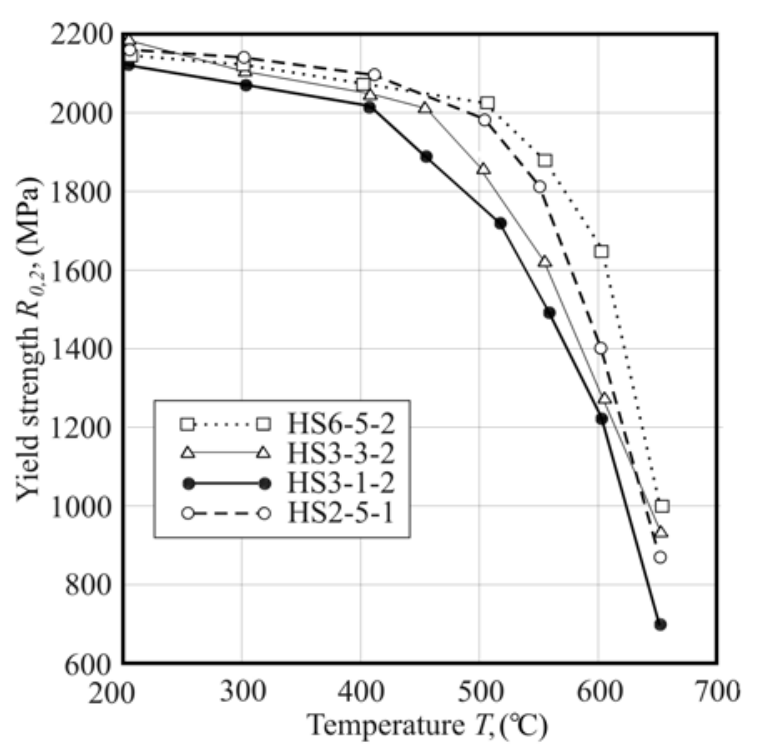

Fig. 6. Dependence $R_{0.2}$ vs. temperature for the HS3-1-2, HS3-3-2, HS2-5-1 and HS6-5-2 steels.

Third range: very intensive $R_{0.2}$ decrease, more than $630 \mathrm{MPa}$ for $50^{\circ} \mathrm{C}$ for each steel grade. Obtained results are comparable to hot hardness measurement results for high-speed steels presented in the literature $[22,25]$.

Limits of insignificant hardness decrease and intensive hardness decrease ranges correspond to limits of intensive or insignificant $R_{0.2}$ decrease, and it also follows from many authors' works (e.g., [11]) that tools of HS6-5-2 steel can still work when the temperature in the cutting zone amounts to $500-550^{\circ} \mathrm{C}$. As the tests have shown, HS6-5-2 steel in this temperature range still retains sufficient hardness. For HS2-5-1 and HS33-2 steels this temperature range is from 450 to $500^{\circ} \mathrm{C}$ and for HS3-1-2 steel, from 400 to $450{ }^{\circ} \mathrm{C}$.

\section{Built-up edge formation}

The physical description of tool wear during technological processes and the need to enlarge tool life requires knowledge of material data, e.g. density, specific heat and coefficient of thermal conductivity [26]. A formation of heat during tool work and the increase of the cutting edge temperature are the results of friction between the tool and stock [11].

The average coefficient of friction on the rake face is the primary factor influenced by the formation of a built-up edge [27, 28]. Built-up edges on tools made of different materials may differ significantly from each other (Fig. 7). On the cutting edge of a cutter made of HS6-5-2 steel, a massive built-up edge is formed (Fig. 7a), which increases the tool rake angle to the value of $\gamma=40^{\circ}-50^{\circ}$. 

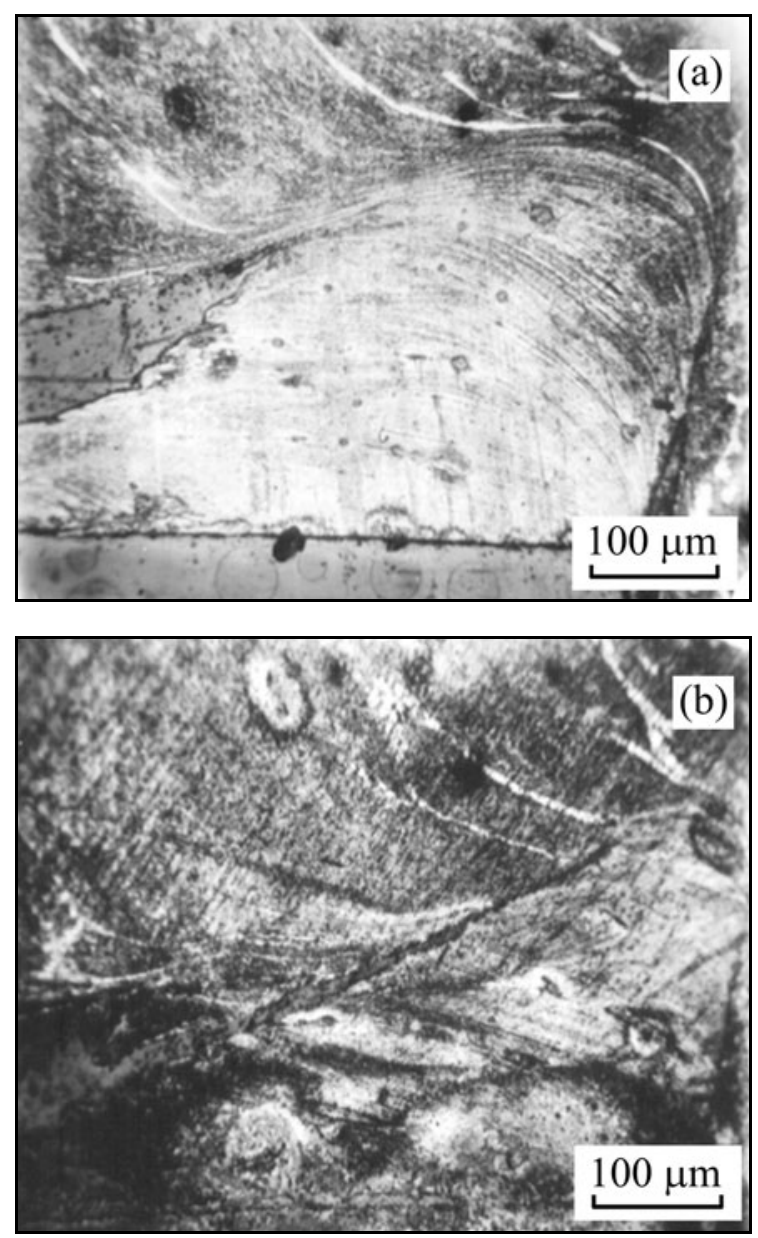

Fig. 7. Built-up edge on the turning tools made of HS65-2 (a) and HS3-1-2 (b) steels: $v_{\mathrm{c}}=30 \mathrm{~m} \mathrm{~min}^{-1}, a_{\mathrm{p}}=$ $0.215 \mathrm{~mm}$, stock is C45 steel, without cooling.

The massive built-up edge protects the tool flank from direct contact with the machined surface and facilitates the chip formation process. Heat generated in the chip formation zone can be greatly accumulated in the built-up edge that protects the blade from its impact. Therefore, the maximum temperature in the cutting edge is determined by the friction of the chip and the rake face and is formed directly at the point of its contact [29]. The built-up edge on the cutter made of HS3-1-2 steel has a lower height (Fig. 7b) and the angle $\gamma=15^{\circ}-20^{\circ}$; it can be assumed that it has less impact on the reduction of friction on the tool flank and, to a lesser extent, protects the cutter from the influence of the heat generated in the chip formation zone and secondary deformations. As a result, the maximum temperature of the knife-edge is formed closer to the main cutting edge below the base of the built-up edge. It was found experimentally that at the large cutting layer thickness, the built-up edge mainly determines the location in the cutting blade that has the highest temperature.

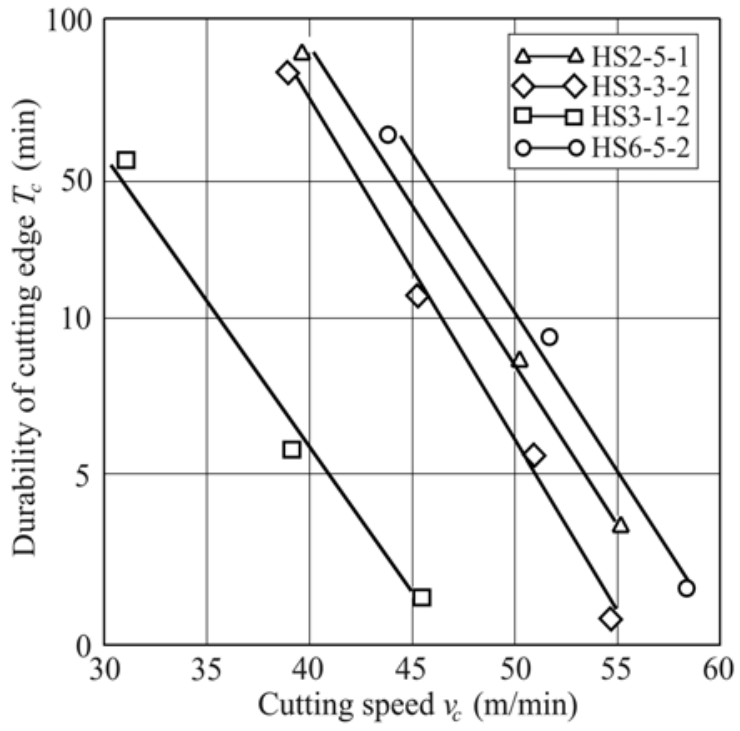

Fig. 8. The durability of cutting edge of cutters made of selected low-alloy high-speed steels with a hardness of 195$220 \mathrm{HB}$ at $f=0.34 \mathrm{~mm} \mathrm{rev}^{-1}, a_{\mathrm{p}}=1 \mathrm{~mm}, \mathrm{VB}=0.5 \mathrm{~mm}$.

Contact with the chip produces a crater in the tool face. Flank wear, on the other hand, is commonly due to friction between the tool and the workpiece material [30]. Different types of wear in high-speed cutting tools have been analysed by Dolinsek et al. [31]. In general, increasing the cutting speed increases the temperature at the contact zone, leading to a drastic reduction of the tool life [30].

\section{Investigation of cutting tool durability}

Figures 8 and 9 show the relationship of the durability of the cutting edge made of HS6-5-2, HS2-5-1 and HS3-3-2 steels in a wide range of cutting speeds, on straight turning the $\mathrm{C} 45$ steel. Investigations of cutters with replaceable inserts were conducted on a lathe with stepless change of speed. All inserts were made according to the same technology and heattreated at optimum temperatures. The design of replaceable inserts was tetragonal with the dimensions of $18 \times 18 \times 8 \mathrm{~mm}^{3}$. After clamping in a special cutter holder the cutting edge geometry was as follows: $\alpha=10^{\circ}, \gamma=8^{\circ}, \chi=45^{\circ}, \chi^{\prime}=15^{\circ}, \varepsilon=120^{\circ}, \beta=$ $72^{\circ}, r_{\varepsilon}=1.5$.

Analysing the research results, it was found that, at both cut layers of thickness, the effectiveness of cutters made of selected high-speed steel grades does not change. The cutters made of HS3-1-2 steel have the lowest durability, those made of HS3-3-2 have the higher durability, and the best results are ensured by cutters made of HS2-5-1 and HS6-5-2 steels. At large cut layer thickness, $f=0.32 \mathrm{~mm} \mathrm{rev}^{-1}$ (Fig. 8), the 


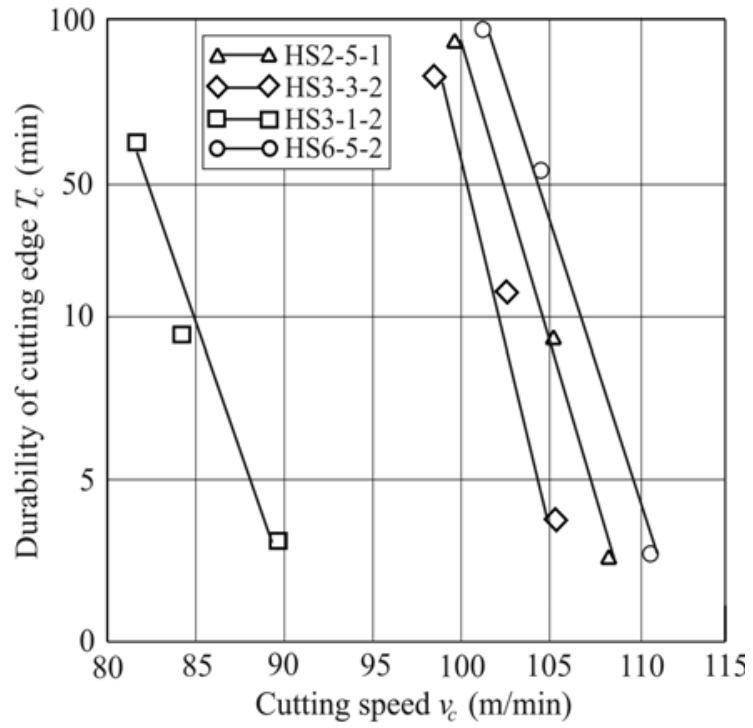

Fig. 9. The durability of cutting edge of cutters made of selected low-alloy high-speed steels with a hardness of 195$220 \mathrm{HB}$ at $f=0.08 \mathrm{~mm} \mathrm{rev}^{-1}, a_{\mathrm{p}}=1 \mathrm{~mm}, \mathrm{VB}=0.5 \mathrm{~mm}$.

cutters made of HS3-1-2 have the same cutting edge durability as the cutters made of HS6-5-2 steel at $30 \%$ lower cutting speed, the cutters made of HS3-3-2 and HS2-5-1 at $10 \%$ lower speed, which is connected with their lower temperability.

Together with the cut layer depth decrease at the feed value of $f=0.08 \mathrm{~mm} \mathrm{rev}^{-1}$ (Fig. 9), the durability of the cutters made of HS3-1-2 steel corresponds to the durability of the cutters made of HS6-5-2 at a cutting speed $25 \%$ lower, and the cutters made of HS3-3-2 and HS2-5-1 steels correspondingly $5 \%$ lower (at 40-minute cutting edge durability). At higher cutting speed, the durability differences are still larger.

The performed tests allow the difference in cutting edge durability for both high speed steel grades at the cutting parameters for which temperature fields were built to be explained. High cutting edge durability for the HS6-5-2 steel cutter of $T_{\mathrm{c}}=450 \mathrm{~min}$ results from the fact that the temperature in the cutting edge is much lower than the temperature at which the decrease in tool material hardness starts $\left(400^{\circ} \mathrm{C}\right)$. In these operating conditions, the main factor affecting cutting edge durability is the wear resistance of HS6-5-2 steel. Turning with the cutter made of HS3-1-2 steel, the temperature near the cutting edge reaches the value at which the process of the hardness decrease starts $\left(325^{\circ} \mathrm{C}\right)$. So, the tool wearing process is connected to progressive hardness loss and also connected to plastic deformation of the cutting edge.

Tool wear is conditioned by progressive hardness loss and connected to its plastic deformation [24], and its durability amounts to only $T_{\mathrm{c}}=60 \mathrm{~min}$.

On turning C45 steel, the cutters made of HS6-5-
2 steel had 40-minute cutting edge durability at the cutting speed $v_{\mathrm{c}}=105 \mathrm{~m} \mathrm{~min}^{-1}$ and were $50 \%$ lower than when turning C60 steel. The same cutting edge durability for the cutters made of HS3-1-2 steel corresponded to the cutting speed $v_{\mathrm{c}}=80 \mathrm{~m} \mathrm{~min}^{-1}$, and was also $50 \%$ higher than when turning C60 steel.

\section{Conclusions}

1. The obtained results show that alloy addition content decrease has not influenced change in the thermal-physical properties of low-alloy high-speed steels.

2. The cause of lower durability of the cutting edges of cutters made of HS3-1-2, HS3-3-2 and HS2$-5-1$ steels is earlier at the start of the process of progressive hardness loss, which for HS3-1-2 steel starts at a temperature lower by $100^{\circ} \mathrm{C}$ and for HS3-3-2 and HS2-5-1 steels lower by $50^{\circ} \mathrm{C}$ than for HS6-5-2 steel.

3. Investigations of cutting edge durability confirm that for defined working conditions of the tool made of high-speed steel the resistance against hardness loss with increasing temperature at temperatures higher and lower than tempering temperature is the most significant.

4. Whereas surface treatments allow steel properties to change only in defined limits, tools made of HS3-1-2, HS3-3-2 and HS2-5-1 cannot work as effectively as tools made of HS6-5-2 steel, particularly at higher cutting speed.

5. Considering total alloy addition content $\% \mathrm{~W}$ $+1.5 \%$ Mo, and particularly very scarce tungsten, on the one hand, and resistance against hardness loss of various high-speed steel grades with temperature increase on the other, it should be stated that an adequate grade ensuring the quality of tools is HS6-5-2 steel.

6. Considering observed tendencies in machining, it seems purposeful to conduct thorough investigations to propose in a well-grounded way, what kind of tools made of which high-speed steel grade can be effectively used.

\section{References}

[1] Trent, E. M., Wright, P. K.: Metal Cutting. 3rd Edition. Woburn, Butterworth-Heinemann 2000.

[2] Pandit, S. M., Kashov, S.: Wear, 84, 1983, p. 65. doi:10.1016/0043-1648(83)90119-9

[3] Bała, P., Pacyna, J., Krawczyk, K.: Kovove Mater., 49, 2011, p. 125.

[4] Berkowski, A.: Wrought High-Speed Steels. Poznań, IOP 1994. (in Polish)

[5] Kowalik, M., Trzepieciński, T.: Arch. Civ. Mech. Eng., 12, 2012, p. 292. doi:10.1016/j.acme.2012.05.002

[6] Kowalik, M., Trzepieciński, T.: Arab. J. Sci. Eng., 39, 2014, p. 1251. doi:10.1007/s13369-013-0722-y 
[7] Mittemeijer, E. J.: Fundamentals of Materials Science. Berlin-Heidelberg, Springer-Verlag 2010.

[8] Bobrov, V. F.: Fundamentals of Theory of Metal Machining. Moscow, Mashinostrojenie 1995.

[9] Jaworski, J.: Arch. Mech. Technol. Automat., 21, 2001, p. 23.

[10] Jaworski, J.: Arch. Foundry Eng., 8, 2008, p. 157. (in Russian)

[11] Sinopalnikov, V. A.: Some Problems of Increasing in Durability of Tools Made of High-Speed Steel. HighProductivity Designs of Cutting Tools. Moscow, MDNTN 1976.

[12] Tönshoff, H., Dankena, B.: Spanen (Grundlagen). Berlin, Springer Verlag 2004.

[13] Walsh, R. A., Cormier, D.: Machining and Metalworking Handbook. 3rd Edition. New York, McGraw-Hill 2006.

[14] Kodácsy, J., Molnár, V.: Int. J. Eng., 9, 2011, p. 169.

[15] Kodácsy, J.: Acad. J. Manuf. Eng., 7, 2009, p. 30.

[16] O'Sullivan, D., Cotterell, M.: J. Mat. Proc. Technol., 118, 2001, p. 301. doi:10.1016/S0924-0136(01)00853-6

[17] Stephenson, D. A.: ASME J. Eng. Ind., 113, 1991, p. 121. doi:10.1115/1.2899668

[18] Jakubéczyová, D., Blach, D., Fáberová, M.: Kovove Mater., 39, 2001, p. 278.

[19] Sharma, V. S., Sharma, S. K., Sharma, A. K.: J. Intell. Manuf., 19, 2009, p. 99. doi:10.1007/s10845-007-0048-2
[20] Jaworski, J.: Int. J. Appl. Mech. and Eng., 9, 2004, p. 493.

[21] Groover, M. P.: Fundamentals of Modern Manufacturing: Materials, Processes and Systems. 4th Edition. Hoboken, John Wiley \& Sons 2007.

[22] Geller, J. A.: Tool Steels. Moscow, Metallurgy 1983.

[23] Helman, P.: High-Speed Steels ASP. Properties and Application Possibilities. Warsaw, Stora Kopparberg 1997.

[24] Jaworski, J.: Acta Metallurgica Slovaca, 7, 2001, p. 178.

[25] Bayer, A. M., Becherer, B. A., Vasco, T.: High-Speed Tool Steels, ASM Handbook: Machining, 16, 1989, p. 51.

[26] Jaworski, J.: Arch. Mat. Sci. Eng., 39, 2009, p. 84.

[27] Cassier, Z., Prato, Y., Muñoz-Escalona, P.: J. Mat. Eng. \& Perform., 13, 2004, p. 542. doi:10.1361/10599490420629

[28] Thamizhmanii, S., Hassan, S.: Int. J. Mater. Form., 2, 2009, p. 531. doi:10.1007/s12289-009-0429-5

[29] Abhang, L. B., Hameedullah, M.: Int. J. Eng. Sci. Technol., 2, 2010, p. 382.

[30] Haber, R. E., Jiménez, J. E., Peres, C. R., Alique, J. R.: Sens. Actua. A, 116, 2004, p. 539. doi:10.1016/j.sna.2004.05.017

[31] Dolinsek, B., Sustarsic, J., Kopac, J.: Wear, 250, 2001, p. 349. doi:10.1016/S0043-1648(01)00620-2 